\title{
Avaliação da redução do índice de placa visível e do índice de sangramento gengival em uma prática de promoção de saúde bucal com crianças
}

\author{
Evaluation of the reduction of the visible plaque index and \\ of the gum bleeding index in a program of oral health \\ promotion for children
}

João Luiz Gurgel Calvet da Silveira*

Valéria de Oliveira*

Wilton Wilney Nascimento Padilha**

\begin{abstract}
RESUMO: O objetivo desta pesquisa foi avaliar a redução de índice de placa visível (IPV) e índice de sangramento gengival (ISG) em crianças atendidas em uma unidade do SUS do RJ. Foi utilizado o método de procedimento comparativo e estatístico (teste $t$ através do programa GMC) para verificar a variação entre as médias do IPV e do ISG iniciais (registrados no início do ciclo de atendimento) e finais (registrados logo após as crianças terem participado de atividades promocionais de saúde com escovação supervisionada semanal, orientação de dieta individual e atividade educativa coletiva com a presença do responsável, bem como adequação do meio bucal e atendimento cirúrgico restaurador, num período médio de 6 meses). População: dados referentes a um grupo de 42 crianças com uma média de idade de 9 anos com 4 dentes afetados pela doença cárie, em média. Utilizou-se a técnica de documentação indireta através de pesquisa documental. Resultados: IPV-inicial $=29 \%$ contra IPV-final $=11 \%$ e ISG-inicial $=13 \%$ contra ISG-final $=5 \%$. As variações encontradas foram estatisticamente significantes ao nivel de $1 \%$ pelo teste estatístico aplicado. O programa de promoção de saúde analisado mostrou-se eficaz em relação ao controle de placa, reduzindo o IPV a um nivel mais aceitável. Embora o ISG tenha sofrido uma redução considerável, a presença de sangramento gengival no final do ciclo de atendimento requer uma melhor abordagem da motivação do paciente em realizar a higiene bucal rotineiramente.
\end{abstract}

UNITERMOS: Saúde bucal; Criança; Escovação dentária.

\begin{abstract}
The purpose of this research was to evaluate the reduction of the VPI (visible plaque index) and of the GBI (gum bleeding index) in children seen at a unit of SUS, in the state of Rio de Janeiro. A comparative and statistical procedure ( $t$-test, by means of the GMC program) was employed in order to assess the variation between initial and final mean VPI and GBI values. Initial values were registered in the beginning of the assistance program, and final values were registered after the children had participated in health promotion activities, which included weekly supervised brushing sessions, individual dietary guidance, collective instructive activities in which parents were present, adjusting of the oral environment, as well as restorative and surgical dental care, during an average period of six months. The studied sample comprised fourty-two children, with an average age of nine years, who presented an average of four teeth affected by caries. The technique of indirect documentation, by means of documental research, was employed. The following results were obtained: initial VPI $=29 \%$; final VPI $=11 \%$; initial GBI $=13 \%$ and final GBI $=5 \%$. The observed variations were statistically significant at the level of $1 \%$, which was revealed by the applied statistical test. The program proved efficient as to plaque control, reducing VPI to a more acceptable level. Although GBI presented considerable reduction, the presence of bleeding at the end of the program calls for a better approach in motivating patients as to regular oral hygiene.
\end{abstract}

UNITERMS: Oral health; Child; Tooth brushing.

\section{INTRODUÇÃO}

Segundo Kuhn ${ }^{7}$ (1982), paradigmas científicos constituem-se em: "realizações científicas universalmente reconhecidas que, durante algum tempo, fornecem problemas e soluções modelares para uma comunidade de praticantes de uma ciência."

No campo do conhecimento odontológico, Wey$\mathrm{ne}^{18}$ (1999) destaca como mudança de paradigma da Odontologia a substituição da abordagem e da

* Doutorandos em Odontologia Social pela Universidade Federal Fluminense.

** Doutor em Clínica Integrada da Universidade Federal da Paraíba. 
Silveira JLGC da, Oliveira V de, Padilha WWN. Avaliação da redução do índice de placa visível e do índice de sangramento gengival em uma prática de promoção de saúde bucal com crianças. Pesqui Odontol Bras 2002;16(2):169-174.

prática cirúrgico-restauradora para a de promoção de saúde, pontuando seu início na década de 60 com a "revolução científica" determinada pela constatação de que a cárie dentária era uma doença bacteriana infecciosa e transmissivel, sendo este fato demonstrado pelas pesquisas de Paul Keyes e Robert Fitzgerald. Tais pesquisas foram o ponto de partida para inúmeros estudos que se estendem até os dias de hoje, abordando o aspecto biológico da doença cárie, destacando-se a especificidade de certos grupos de bactérias no processo cariogênico, os mecanismos da janela de infectividade, e a transmissibilidade ${ }^{3,5,9,10,15}$

Corroborando com o paradigma de promoção de saúde, acima descrito, Elderton ${ }^{4}$ (1997) alerta para o risco de o profissional ingressar no ciclo restaurador repetitivo, ao adotar a abordagem restauradora tradicional, condizente com o paradigma cirúrgico-restaurador, que preconiza uma intervenção mecânica para solucionar problemas de ordem bacteriológica, levando a um agravamento do quadro patológico, que resulta na manutenção da doença e na "re-restauração" do dente restaurado, aumentando em complexidade e gravidade as intervenções do profissional, culminando, com o passar do tempo, com a perda do elemento dentário.

Portanto, um programa de assistência odontológica inserido no paradigma de promoção de saúde deve desenvolver também ações educativas e preventivas sem limitar-se às atividades curativas.

A adequação do meio bucal caracteriza-se em atividade clínica que consiste no selamento de cavidades abertas, remoção de fatores retentivos de placa como excessos ou falhas em restaurações, remoção de cálculo, profilaxia e aplicação de flúor.

Identificada com os princípios que norteiam o paradigma de promoção de saúde, a justificativa para a realização da adequação do meio bucal, antes de iniciar as atividades restauradoras necessárias ao restabelecimento da função e da estética dos elementos dentários afetados por cavidades, baseia-se em critérios científicos e constitui-se num procedimento que visa controlar o nível de colonização microbiana cariogênica, associada a fatores retentivos de placa bacteriana, buscando-se resgatar o padrão ecológico do meio bucal apresentado pelo paciente antes do desenvolvimento da doença cárie.

Segundo Medeiros ${ }^{11}$ (1998), "as evidências acumuladas na literatura demonstram que, quando a doença cárie apresenta lesões cavitadas, o número de colônias microbianas aumenta significativamente, pois as lesões cavitadas oferecem tudo aquilo que é necessário para manter seu ciclo vital.
Dessa forma, ao compararmos o número de unidades formadoras de colônias de estreptococos do grupo mutans e de lactobacillos em pacientes sem lesões cavitadas e com lesões cavitadas, observamos uma superioridade para aqueles pacientes que apresentam lesões cavitadas". Por esse motivo, o mesmo autor recomenda a remoção da maior quantidade possivel de tecido cariado, profilaxia criteriosa, utilização de solução antimicrobiana para bochecho, aplicação de substâncias cariostáticas nas lesões e selamento provisório com cimentos ionoméricos de primeira geração.

Defendendo o mesmo procedimento, Serra et $a l^{14}$ (1997) recomendam a adequação do meio bucal e o controle da doença cárie antes de se iniciar as atividades cirúrgico-restauradoras, propondo que: “ (...) Antes de exigir do indivíduo um controle efetivo de placa, é preciso remover os fatores ou nichos que favoreçam sua retenção, tais como cavidades abertas e restaurações deficientes."

Criticando as decisões restauradoras sem maior reflexão e baseadas na "crença de que a restauração de dentes é a função primária do cirurgião-dentista", Krammer et al. ${ }^{6}$ (1997) recomendam a ampliação do campo de atividades do profissional de Odontologia para além da atuação cirúrgico-restauradora como prioridade, destacando a necessidade de se incorporar atividades promocionais de saúde educativas e preventivas.

O planejamento das atividades de atenção à saúde, sejam elas preventivas, educativas ou curativas, numa abordagem individual ou coletiva, necessita ser baseado em informações e dados, o mais realistas possivel, fornecendo um panorama da quantidade e da intensidade com que um determinado problema atinge os diferentes grupos que compõem a população à qual se destina o programa de atendimento.

Com a finalidade de conhecer as características da manifestação das doenças e dos agravos à saúde em uma população, o planejador de saúde faz uso, na fase de diagnóstico, de informações baseadas em levantamentos epidemiológicos que deverão determinar as ações e as atividades a serem desenvolvidas no programa proposto. Como instrumentos indispensáveis para esse fim destacam-se os índices e indicadores que são termos que apresentam diferentes significados.

Segundo Striffler apud Pinto ${ }^{13}$ (2000), enquanto os indices “(...) sempre se expressam por valores numéricos precisos, os indicadores de saúde possuem um sentido mais amplo e podem incluir tanto alguns índices quanto informações qualitativas como acesso a serviços de saúde, a oferta de 
Silveira JLGC da, Oliveira V de, Padilha WWN. Avaliação da redução do índice de placa visível e do índice de sangramento gengival em uma prática de promoção de saúde bucal com crianças. Pesqui Odontol Bras 2002;16(2):169-174.

mão-de-obra, a correspondência entre problemas de saúde bucal e as condições de vida, etc.". O mesmo autor destaca que os índices são empregados em estudos de prevalência e incidência de problemas de saúde para fins operacionais ou de pesquisa e devem apresentar como características, preferencialmente: 1) clareza, simplicidade e objetividade; 2) validez; 3) confiabilidade; 4) sensibilidade e 5) aceitabilidade.

O objetivo deste trabalho foi avaliar, sob uma abordagem coletiva, a eficácia de um programa de saúde bucal, através da verificação da redução da placa bacteriana e da presença de sangramento gengival em crianças de 4 a 13 anos de idade.

\section{MATERIAIS E MÉTODOS}

Este estudo foi realizado com crianças de 4 a 13 anos de idade, submetidas a um programa de promoção de saúde bucal em uma unidade de atenção básica de saúde do SUS, através do Programa de Integração Docência-Assistência da Secretaria Municipal de Saúde do Rio de Janeiro - Coordenação de Saúde Bucal, com a participação de professores e alunos do $9^{\circ}$ período da graduação de Odontologia da Universidade Estácio de Sá (UNESA). Os dados são referentes ao $1^{\circ}$ semestre de 1999 e foram colhidos a partir dos registros realizados pelos alunos durante o atendimento. Os indices eram verificados pelo mesmo aluno no início e no final do ciclo de atendimento, anotado na ficha clinica e transcrito para o mapa de registro, de onde foram retirados os dados.

O referido programa consta de atividades promocionais de saúde com escovação supervisionada semanal, orientação de dieta numa abordagem individual e atividades educativas coletivas, com a presença do responsável ou acompanhante da criança.

Como atendimento clínico destaca-se o exame minucioso da cavidade bucal, com registro dos indicadores da condição encontrada, na ficha individual da criança, seguido da adequação do meio bucal complementado pelo tratamento cirúrgico restaurador necessário. O ciclo de atenção tem duração média de 6 meses, sendo as crianças agendadas para retorno de acordo com a avaliação de seu risco individual, podendo variar de 3 meses a 1 ano.

Utilizou-se o IPV (indice de placa visivel) para a aferição da condição de higiene bucal apresentada pela criança no momento em que ela entra no programa (IPV-inicial), antes de receber qualquer informação ou orientação prática no escovário sobre escovação e uso de fio dental. No momento do encerramento do ciclo de atividades promocionais e clínicas, a criança é submetida a outra aferição da sua condição de higiene (IPV-final) para fins de comparação da evolução da melhoria da sua performance em controlar a placa.

O mesmo procedimento é adotado em relação ao periodonto, utilizando-se para a sua avaliação o ISG (indice de sangramento gengival) inicial e final.

Os índices ceo, CPO e ICS (indice de consumo de sacarose) não foram analisados para fins deste trabalho, que serve ao propósito de avaliar o referido programa de atenção quanto ao seu objetivo de melhorar o controle de placa das crianças atendidas, demonstrando também a utilização prática de indices e indicadores de saúde bucal e sua aplicação no planejamento das atividades numa prática de promoção de saúde, seja numa abordagem clínica individual, voltada para a atuação do profissional liberal, ou coletiva, identificada com as necessidades de programas de saúde.

A metodologia de pesquisa utilizada neste trabalho foi fundamentada em Lakatos, Marconi ${ }^{8}$ (1991), sendo caracterizada por método de abordagem indutivo com procedimento comparativo e estatístico. Procedeu-se com a análise comparativa dos índices de placa visível e de sangramento gengival iniciais (registrados na primeira consulta) e finais (registrados na última consulta, após a participação das crianças no ciclo de atividades promocionais de saúde e clínicas).

Para a aferição do IPV-inicial, na primeira consulta, foram contabilizadas as superficies dentárias (faces) suscetíveis ao acúmulo de placa presentes na cavidade bucal da criança, excluindo-se as faces incisais. Logo após, foram contabilizadas as superficies que apresentavam placa bacteriana, procedendo-se a uma operação matemática (regra de 3 simples) para determinar o valor relativo (porcentagem) de faces afetadas em relação ao total de faces. O mesmo procedimento era adotado para a aferição do IPV-final.

$\mathrm{Na}$ aferição do ISG inicial e final, procedeu-se da mesma maneira, sendo excluídas, na contabilização das superficies dentárias presentes na cavidade bucal, as oclusais e incisais por não apresentarem relação com o sulco gengival.

Cabe destacar que o examinador que atendia a criança na primeira consulta era o mesmo ao final do ciclo de atendimento, tendo sido capacitado e supervisionado pelo mesmo professor responsável, num processo de calibração, o que nos possibilitou a utilização dos dados para fins desta pesquisa. 
Silveira JLGC da, Oliveira V de, Padilha WWN. Avaliação da redução do índice de placa visível e do índice de sangramento gengival em uma prática de promoção de saúde bucal com crianças. Pesqui Odontol Bras 2002;16(2):169-174.

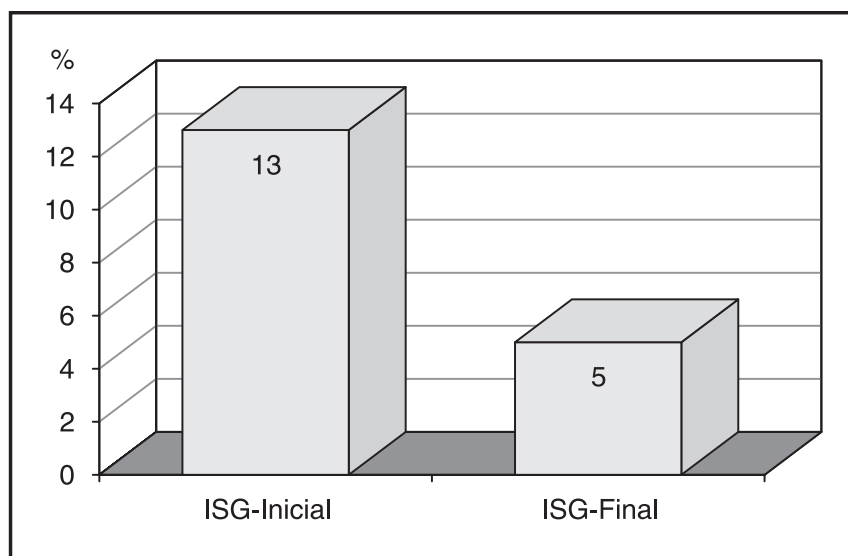

GRÁFICO 1 - Relação entre índice de sangramento gengival (ISG) inicial e final.

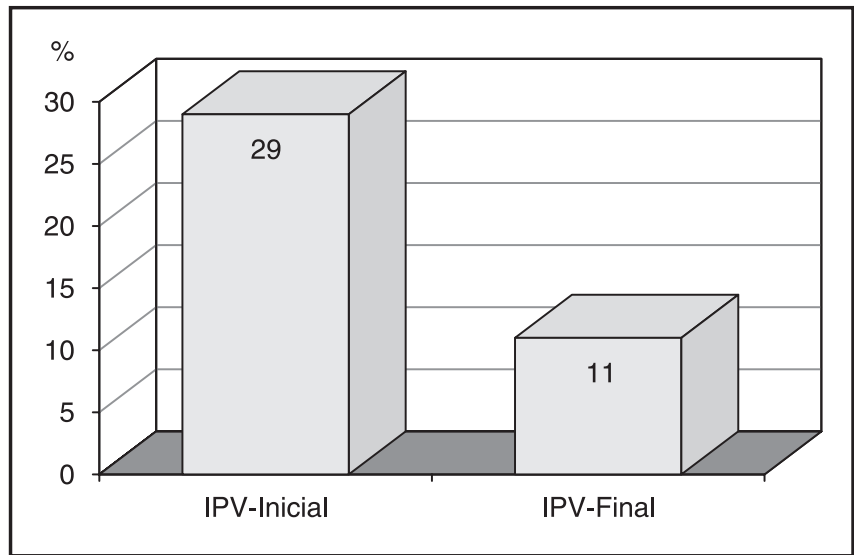

GRÁFICO 2 - Relação entre índice de placa visível (IPV) inicial e final.

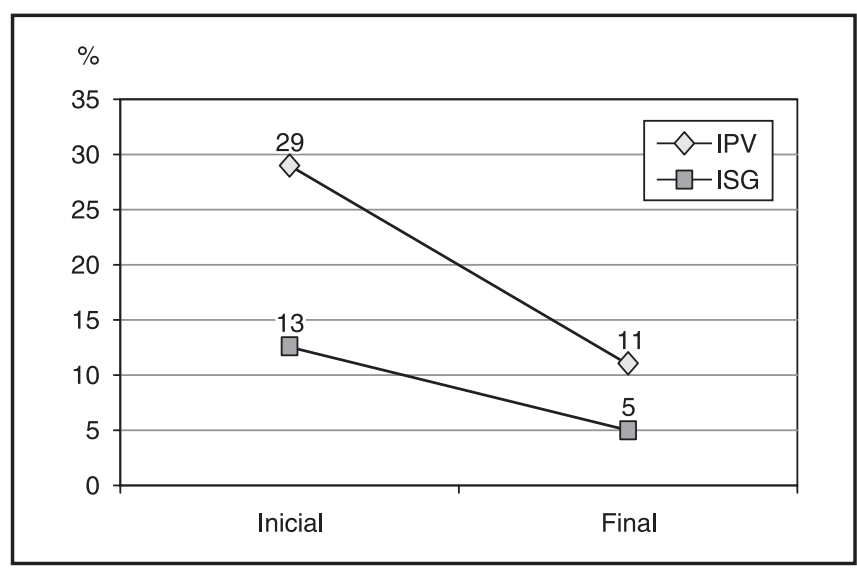

GRÁFICO 3 - Relação da variação entre índice de placa visivel (IPV) e índice de sangramento gengival (ISG) inicial e final.

Para a análise estatística, com a finalidade de verificar a variação ocorrida entre as médias de IPV e de ISG iniciais e finais utilizou-se o teste $t$ através do programa GMC (versão 6.5 - 10/09/93. Prof.
Geraldo Maia Campos, Faculdade de Odontologia de Ribeirão Preto da USP, disponibilizado pelo autor na forma de disquete de $31 / 2$ polegadas).

A técnica de pesquisa foi a documentação indireta através de pesquisa documental, tendo como fonte de dados os mapas de registro de atividades desenvolvidas durante um ciclo de ações de 6 meses. A população foi composta por 42 crianças com uma média de 9 anos de idade.

Cabe destacar que nenhuma criança foi submetida a qualquer tipo de procedimento (exame bucal) ou entrevista para fins dessa pesquisa pois os dados foram colhidos dos mapas de registros estatísticos sem a menor possibilidade de identificação das crianças envolvidas, dando um caráter coletivo aos dados.

\section{RESULTADOS}

Os valores registrados entre o IPV-inicial médio de $29 \%$ comparado com o IPV-final médio de $11 \%$ no mesmo grupo demonstra uma redução significante, o mesmo ocorrendo com o ISG-inicial médio de $13 \%$ que foi reduzido para $5 \%$ no final do ciclo de atendimento.

A análise estatística utilizando-se o teste $t \mathrm{em}$ amostras vinculadas pode determinar se algum tratamento realizado entre as amostragens teve o dom de modificar os parâmetros analisados e se essa modificação é significante. Nesse caso, analisamos os índices médios IPV e ISG antes e após o ciclo de atendimento, obtendo como resultados: para o IPV, com grau de liberdade 41, um valor calculado de $t$ de 6,79 com significância estatística ao nivel de $1 \%(\mathrm{p}=0,00 \%)$ e para ISG, com grau de liberdade de 41, um valor de $t$ de 4,39 com significância estatística igualmente de $1 \%(\mathrm{p}=0,002 \%)$.

\section{DISCUSSÃO}

Os índices utilizados como dados de análise nesta pesquisa não foram colhidos para essa finalidade mas sim como rotina no programa de atenção de saúde bucal já mencionado, servindo como um dos parâmetros para se analisar o risco da criança em relação ao desenvolvimento da doença cárie, considerando-se o fator placa bacteriana.

Destacamos a importância de se registrar o índice de placa apresentado pelo paciente no momento em que ele entra em contato com o programa e ao final do seu ciclo de atendimento, com dupla finalidade: informar ao profissional sobre a necessidade individual da criança em melhorar o seu controle de placa e servir como parâmetro de avaliação da melhoria da sua performance e numa 
Silveira JLGC da, Oliveira V de, Padilha WWN. Avaliação da redução do índice de placa visivel e do índice de sangramento gengival em uma prática de promoção de saúde bucal com crianças. Pesqui Odontol Bras 2002;16(2):169-174.

abordagem coletiva servir como avaliador da eficácia do programa de promoção de saúde.

A redução do IPV médio alcançada pelo programa pode ser considerada satisfatória, sendo da ordem de $60 \%$ entre o IPV inicial e final.

O IPV médio registrado no final do tratamento também pode ser considerado satisfatório se considerarmos que a desorganização da placa bacteriana, através da escovação pelo paciente, deve ser incentivada mas sem o intuito de atingir o índice de placa zero.

Valença et al. ${ }^{16}$ (2001), em pesquisa semelhante, comparando a redução de biofilme sobre as superficies dentárias entre 31 crianças de 6 a 12 anos, através do registro de IHOS antes e depois de um ciclo de atividades educativas, constataram redução significativa desse índice, ressaltando a necessária motivação dos pais, juntamente com a participação ativa e contínua de professores e profissionais de saúde.

Quanto ao comportamento do ISG, os resultados obtidos estão de acordo com trabalho semelhante, realizado posteriormente, que constatou uma redução significante desse índice, utilizando a mesma metodologia com uma amostragem de 379 pacientes, submetidos ao mesmo programa de atividades ${ }^{12}$.

Ainda em relação ao ISG, observa-se que a presença de baixo índice de placa avaliada na consulta, associada ao sangramento gengival, pode significar que o paciente possui uma boa capacidade motora para remover a placa, através de escovação e uso de fio dental, embora não o faça com a freqüência necessária no seu dia-a-dia, desencadeando a inflamação incipiente da região do sulco gengival, sendo indicada uma abordagem mais criteriosa da sua motivação do que da técnica por ele empregada.

Destaca-se ainda que a presença de pontuação no ISG final pode significar falha no exame ou no registro desse índice. Uma medida recomendável seria a revisão dos casos em que o índice final não atingiu o índice zero para se buscar as causas pos-

\section{REFERÊNCIAS}

1. Barros ACTAP, Azevedo MEA, Silveira JLGC, Abreu FVG. O processamento da informação a partir de uma atividade educativa em saúde bucal. Rev Fluminense de Saúde Coletiva 1998;5:7-13.

2. Cabral ICT, Burun SC. Motivação: o grande desafio. Rev Fluminense de Saúde Coletiva 1998;4:23-32.

3. Caufield PW, Ratanapridakul K, Allen DN, Cutter GR. Plasmid containg strains of Streptococcus mutans cluster wit- siveis. Tal procedimento pode ser realizado na totalidade dos casos ou através de uma amostragem. No caso estudado, o ISG final pode ser considerado satisfatoriamente baixo.

Estudo de Barros et al. ${ }^{1}$ (1998) demonstrou que o processamento de informações por crianças em programas educativos de saúde parte de noções concebidas no meio familiar e social podendo este conhecimento ser aprimorado através de programas educativos. Volschman et al. ${ }^{17}$ (2000) relacionam ainda o conhecimento e crenças sobre saúde bucal entre crianças com o nivel de escolaridade.

Destaca-se, dessa maneira, a importância dos registros realizados na ficha clínica individual do paciente, que devem ter uma utilidade clara e uma aplicação prática para o profissional que realiza o exame e o preenchimento da ficha, para não se tornarem meros dados burocráticos. Quando isso ocorre, pode resultar em fichas mal preenchidas, com campos em branco ou dados não confiáveis, comprometendo a avaliação de um programa de saúde coletiva ou até mesmo a avaliação da evolução individual do paciente frente às intervenções do profissional, numa prática do modelo liberal de atendimento.

\section{CONCLUSÃO}

O programa de promoção de saúde analisado mostrou-se eficaz em relação ao controle de placa, reduzindo o IPV médio das crianças atendidas a um nivel aceitável.

Embora o ISG médio tenha sofrido uma redução considerável, a presença de sangramento gengival no final do ciclo de atendimento requer uma melhor abordagem da motivação do paciente em realizar a higiene bucal rotineiramente.

Os registros realizados na ficha clínica individual ou mapas estatísticos podem ter uma aplicação direta na avaliação e reorientação das atividades realizadas tanto coletivamente em programas de saúde quanto individualmente no modelo liberal da profissão odontológica, conforme demonstrado por esta pesquisa.

hin family and racial chorts: implication for natural transmission. Infec Imun 1988;56:3216-20.

4. Elderton RJ. Ciclo restaurador repetitivo. In: Kriger L. ABOPREV - promoção de saúde bucal. São Paulo : Artes Médicas; 1997. p. 194-249.

5. Kölher B, Bratthall D. Intrafamilial levels of Streptococcus mutans and aspects of the bacterial transmission. Scand $\mathrm{J}$ Dent Res 1978;86:35-42. 
Silveira JLGC da, Oliveira V de, Padilha WWN. Avaliação da redução do índice de placa visível e do índice de sangramento gengival em uma prática de promoção de saúde bucal com crianças. Pesqui Odontol Bras 2002;16(2):169-174.

6. Krammer PF, Feldens CA, Romano AR, Oppermann RV. Promoção de Saúde Bucal em Odontopediatria. São Paulo: Artes Médicas; 1997.

7. Kuhn TS. A estrutura das revoluções científicas. São Paulo: Perspectiva; 1982.

8. Lakatos EM, Marconi MA. Fundamentos de Metodologia Científica. $3^{a}$ ed. São Paulo: Atlas; 1991.

9. Löe H. Oral hygiene in the prevention of caries and periodontal disease. Int Dent J 2000;50:129-39.

10. Loesche WJ. Cárie dental: uma infecção tratável. Rio de Janeiro: Cultura Médica; 1993.

11. Medeiros UV. Controle da doença cárie. In: Galan J, Namen FM. Dentística restauradora - o essencial para o clínico. São Paulo: Santos; 1998. p. 8-47.

12. Mello PBM, Maia KD, Gama VRCM, Weynw SC. Índice de sangramento gengival: avaliador de promoção de saúde bucal. Pesqui Odontol Bras 2001;15 suppl:21.

13. Pinto VG. Saúde Bucal Coletiva. $4^{\mathrm{a}}$ ed. São Paulo: Santos; 2000. p. 139-222.

14. Serra MC, Pimenta LAF, Paulillo LAMS. Dentística e manutenção de saúde bucal. In: Kriger L. ABOPREV - promoção de saúde bucal. São Paulo: Artes Médicas; 1997. p. 203-49.

15. Svanberg M. Contamination of toothpaste and toothbrush by Streptococcus mutans. Scand J Dent Res 1978;86: 412-4.

16. Valença AMG, Santos MEO, Amaral MAT, Graça TCA, Bastos VAS. Promoção de saúde bucal em pacientes da disciplina de Odontopediatria da Faculdade de Odontologia da Universidade Federal Fluminense. [periódico on-line] 2001 [artigo científico]. Disponivel em: http://www.odontologiainfantil.8m.com/publicacoesa16htm >. Acesso em: 30 ago. 2001.

17. Volschman B, Silveira F, Naegele MA, Alves MU. Conhecimentos e crenças sobre saúde bucal. Pesqui Odontol Bras 2000;14 suppl:112.

18. Weyne SC. A construção do paradigma de promoção de saúde - um desafio para as novas gerações. In: Kriger L. ABOPREV - promoção de saúde bucal. 2 ed. São Paulo: Artes Médicas; 1999. p. 2-24. 